\title{
Tendência e concretismo
}

\author{
Rui Mourão*
}

O grupo formado basicamente por mim, Fábio Lucas e Affonso Ávila, depois de lançar por volta de 1950 a revista Vocação, que nos apresentaria como escritores, tornou a reunir-se nos últimos anos daquela década, mas não apenas com o propósito de editar uma publicação a mais. Em plena juventude, com a ambição e o idealismo próprios da idade, planejávamos iniciar uma pesquisa literária que nos permitisse realizar obra inovadora, vinculada ao momento histórico por nós vivido. Que estava empurrando para frente aqueles jovens tão estouvados, talvez pretensiosos?

O país, na fase democrática do governo Getúlio Vargas, assistia ao primeiro grande surto desenvolvimentista do período republicano. A política do voto de cabresto dos coronéis, exercida pelos proprietários de terra, sofreria os primeiros abalos com a chamada "marcha dos 18 do forte de Copacabana", realizada pelos tenentes, que reivindicavam em favor da classe média. Na década seguinte, o governo dava início à criação do parque industrial, que teve como consequência o surgimento de centros populosos, onde começariam a aparecer massas operárias com disposição de assumir posição política, facilitando a circulação de ideias socialistas e abrindo espaço para a fundação do partido comunista. Era como o alvorecer de um mundo novo. Havia sido recente a criação da Siderúrgica Nacional em Volta Redonda, empreendimento de grande porte. A campanha do "petróleo é nosso" incendiava as ruas. O presidente da República, naquele momento radicalmente posicionado à esquerda, em seu último discurso, de lançamento da Siderúrgica Mannesmann em Belo Horizonte, iria dizer para arrepio das oligarquias nacionais bem pensantes, que o cruzeiro tinha a estranha faculdade de parir dólares.

A administração seguinte, de Juscelino Kubitschek, consagrada por um programa de feições indiscutivelmente alucinatórias, a princípio taxado de demagógico, retomou o mesmo caminho. "Cinquenta anos em cinco" foi o plano

\footnotetext{
* Romancista e ensaísta, um dos criadores da revista Tendência (1957-1962), de Belo Horizonte e diretor do Museu da Inconfidência, em Ouro Preto. É autor dos romances Boca de chafariz, Curral dos crucificados, Quando os demônios descem o morro e vários outros.
} 
que os brasileiros, envaidecidos, puderam comemorar. A indústria se expandiu com as fábricas de automóveis e a implantação do estaleiro naval, que numa ação em cadeia, impuseram o aparecimento de outras iniciativas a elas relacionadas. Estradas de rodagem foram rasgadas de norte a sul do país. Teve início a construção de Brasília, impondo a expansão do comércio e o surgimento de centenas de fábricas produtoras dos materiais famintamente consumidos pela obra de proporções desmedidas que em ritmo galopante se implantava no planalto central.

Arrastados naquele roldão, acometidos por ideias nacionalistas, os setores intelectuais entregavam-se à tarefa do estabelecimento das linhas de um pensamento unitário, abrangente e criador, que viesse impor racionalidade a tudo o que acontecia na base da sociedade. O Instituto Superior de Estudos Brasileiros - ISEB surgiu com a ambição de criar uma ideologia brasileira extensiva aos múltiplos setores do saber. A universidade nos campus de maior prestígio - devendo-se fazer registro especial para a Universidade do Distrito Federal, criada por Anísio Teixeira - , embarcou por completo na onda nacionalista. O nosso pequeno grupo de Belo Horizonte, no âmbito da sua área de atividade, levantou a bandeira da revista Tendência, que logo receberia adesão de outros intelectuais.

Queríamos nos comprometer com a pesquisa de uma linguagem buscadamente lastreada na realidade nacional. À primeira vista o projeto soava repetitivo numa literatura como a nossa, sempre atenta à realidade, na esperança da conquista da sua maneira autônoma de ser. A verdade é que constituía tarefa das mais difíceis, na altura dos anos em que para nós ele se apresentou. A questão crucial era saber o que de fato poderia ser entendido como conteúdo nacional, naquele momento da cultura avançada do mundo e do Brasil. Existia a tradição regionalista que viera evoluindo desde os primórdios das manifestações ufanistas, mas evidentemente não iríamos nos comprometer com o exótico para realizar algo superado pela literatura do ocidente, de que éramos parte integrante. A tipicidade local sem dúvida não deixava de ser um trunfo a nossa disposição, mas não para ser barateado na condição de um produto meramente conteudístico, fórmula já cediça, de notório envelhecimento, que não podia mais ser do interesse de ninguém.

O esforço para definir o nacional sem cair nas malhas do reducionismo regional consumadamente ingênuo teve início ainda no Modernismo de 1922. Mário de Andrade, ao criar o personagem-símbolo Macunaíma, o qualificou como herói sem nenhum caráter. Oswald de Andrade, no Manifesto Antropofágico, encontrou maneira mais aceitável para definir as condições em que o nacional poderia chegar a impregnar a manifestação atualizada do internacional. Cabia à cultura da diferença devorar o que chegava de fora e devolvê-lo após uma digestão bem feita. 
Em nossas discussões internas do grupo de Tendência (1957) eu defendia que, entre o nacional e o internacional se estabelece uma confrontação de natureza dialética, obtendo-se através desse processo um produto novo, misto de um e de outro, quer dizer, diferente de um e de outro. Mais tarde, Fritz Teixeira de Salles chegaria a formulação rigorosamente literária para facilitar a compreensão da mecânica do processo. Lembrou o autor de Literatura e consciência nacional (Data) que, segundo colocação de Roman Jakobson, uma das tarefas essenciais da linguagem é "vencer o espaço, abolir a distância, criar contiguidade espacial, encontrar e estabelecer uma linguagem comum". Por outro lado, George Lukács estabelecendo os conceitos de singularidade, particularidade e universalidade, segundo os quais a mediação entre a particularidade e a universalidade se opera pela categoria da singularidade, tornou possível a compreensão de que, havendo desconexão do elemento espacial, onde se encontra a particularidade, e do tempo, onde se encontra a universalidade, ocorre uma deformação do produto estético acabado, pois o ponto alto da linguagem só é alcançado quando se verifica a fusão daqueles polos antagônicos. Aumentando a representação espacial, há redução da representação do tempo, e vice-versa. A relação espaço-tempo corresponde àquela dos pratos de uma balança, que se equilibra quando se eliminam as distorções. Para um lado elas conduzem ao estático, ao puramente típico ou anedótico, para o outro, ao excesso de dinamismo, ao francamente atípico ou abstrato.

Dentro do nosso grupo eu cuidava da ficção, Affonso da poesia. Ele percebeu, cabia-lhe descartar a influência da chamada Geração de 45, que de certa forma marcara os conjuntos de "O açude", "Sonetos da descoberta" e "Glosa de primavera" da sua fase inicial, e se enveredar pelo caminho altamente positivo aberto por Carlos Drummond de Andrade, em seguida retomado, com mais intensidade, por João Cabral de Mello Neto. Na passagem do primeiro para o segundo, ocorrera o abandono do conteudo lírico-subjetivo e a apropriação de um verso objetivado, antidiscursivo, despojado ao máximo e substantivado. O desafio a enfrentar não era nada fácil. Pretendendo se formar ao lado dos poetas de maior evidência e modernidade no país naquele momento, Affonso se achava ainda convicto da necessidade de manter fidelidade aos postulados da revista Tendência, que haveria de marcar a sua contribuição pessoal. Na primeira investida para abandonar o reduto das emoções pessoais e sair para a realidade exterior, ele buscou apoio no elemento telúrico ao produzir os poemas "O Boi e o Presidente", "Concílio dos Plantadores de Café", “As Viuvas de Caraguatá", "Os Negros de Itaverava" reunidos em Outra poesia (2006), caindo nas malhas da vertente verde-amarela da fase integralista de Cassiano Ricardo. Mas aquilo foi só 
o primeiro passo. Conforme declararia no livro O poeta e a consciência crítica (2006), "o prosseguimento no estudo do problema criativo e a evolução dialética do pensamento estético-ideológico de Tendência indicaram-nos a necessidade de arguir a coisa nacional em si, determinar o comportamento e a essência do ser numa dada realidade que é a brasileira". Deixando de lado o "elemento apenas conjuntural", ele pôde pesquisar nova forma de expressão válida para uma literatura de específica autenticidade brasileira, dentro de categorias valorativas internacionais.

Carta do solo (2006) marcou o encontro do modelo de poesia preconizada pela estética do grupo de Tendência. A linguagem foi inteiramente objetivada e substantivada. Com o emprego de uma continuidade não linear, a discursividade viu-se estancada. Versos de segmentos sempre interrompidos, até porque se tornavam em parte apenas repetitivos, começavam dando a impressão de que seriam idênticos ao que vinha em seguida. Cada um era igual ao anterior e ao posterior, antes de se modificar pelas palavras justapostas, em posição anterior ou posterior: "A pedra/ com suas ausências/A flor/ com suas ausências/O fruto/ com suas ausências" ou "Com seus arcos aos ofídios/gerou suas ovas de incúrias/ -- aos ofídios com seus cimbalos / tomou no vidro das unhas/ -- aos ofídios com seu lastro/ cevou nos odres da fome". Cada unidade se apresentava diferente, fazendo questão de parecer igual. O que se lia não passava de um continuado refrão quebrado na sua monotonia repetitiva pelo aparecimento de um mote ou um complemento de afirmações, até surgir o arredondar significativo final.

Em São Paulo, os poetas concretistas vinham agitando um debate estético de grande repercussão. Reconhecendo como nós a precedência de Drummond e João Cabral, os teóricos formados em torno da revista Invenção preconizavam uma poesia de objetividade absoluta, concreta e visual, e combatiam o danunzianismo, que estigmatizavam como o máximo do lirismo subjetivo. Apoiavam num slogan propagandístico forjado por Décio Pignatari: Quanto mais síntese, mais poesia; quanto mais discursividade, menos poesia. O que víamos de condenável neles era o extremo formalismo. Não fazendo distinção entre a estrutura do significante e a estrutura do significado, elementos coexistentes e inseparáveis da obra de arte, a ponto de qualquer modificação de um resultar em transformação do outro, chegaram a propalar que a forma era o conteúdo da poesia.

A situação política brasileira, embarcada na onda nacionalista e na necessidade de dar combate à ditadura militar - suporte da dominação das grandes corporações nacionais e estrangeiras - dava sinais de não ter volta. Chegou o momento em que não existia uma só consciência lúcida da intelectualidade brasileira que pudesse ser 
acusada de absenteísmo. Não seria o grupo concreto, a despeito da sua aparência de estetas fechados em torre de marfim, que havia de estar contra aquela corrente. Uma proposta fechada, elitista como a que defendiam, os colocava em direção oposta ao interesse nacional. No congresso de escritores realizado na cidade de Assis, em São Paulo, os integrantes da revista Invenção anunciariam o que denominaram "o pulo da onça" - um salto participante. Affonso Ávila, presente no encontro, declarou que eles estavam era vindo para o lado de Tendência. A posição nova ali defendida coincidia com os postulados do movimento mineiro. Houve a aproximação dos dois grupos e o estabelecimento de um diálogo, através de cartas, que foi publicado no número quatro de Tendência.

Os concretos enquanto pessoas assumiram posições políticas progressistas, principalmente Décio Pignatari, mas no plano da criação literária, não chegaram a encontrar saída que correspondesse à ideologia abraçada. Do nosso lado, Affonso Ávila, que era o poeta do grupo, continuou trabalhando bem seus poemas contextualizados e pôde adotar soluções técnicas inovadoras, lançadas pelos paulistas. Por ter colocado de lado o orgulho, a vaidade - por ter se entregado de fato ao desejo de união - o melhor daquela aliança que efetivamente não houve, aconteceu do lado mineiro. Affonso Ávila foi quem realizou a poesia de maior consistência da vanguarda vigente no Brasil a partir dos últimos anos da década de 1950.

Referências

AGUIAR, Melânia da Silva de. Fortuna crítica de Affonso Ávila. Belo Horizonte: Secretaria de Estado de Cultura de Minas Gerais e Arquivo Público Mineiro, 2006. 
